\title{
PERCEPÇÃO AMBIENTAL E ANÁLISE DE DESENHOS: PRÁTICA EM CURSO DE EXTENSÃO UNIVERSITÁRIA
}

\author{
Felipe Alan Souza Santos ${ }^{1}$ \\ Natali Oliveira Santos Eckert ${ }^{2}$ \\ Rejane Santos Oliveira ${ }^{3}$ \\ Humberto Gomes da Silva Neto 4 \\ Leisitânia Nery Teixeira ${ }^{5}$ \\ Andressa Sales Coelho ${ }^{6}$
}

Resumo: O presente artigo se propõe construir uma descrição metodológica para análise de desenhos. O objetivo principal é descrever uma metodologia de análise de desenhos para compreender a percepção dos indivíduos e suas relações com o meio ambiente. A metodologia da pesquisa adaptou o método de análise de conteúdo de Bardin (2006). Foram criadas categorias, observando-se desenhos realizados em atividades de extensão universitária ministradas, no ano de 2015, e as similaridades dos desenhos resultaram na elaboração de quatro categorias de análise de desenhos: Percepção Romântica, Percepção Pessimista, Percepção de Dominação e Percepção de Sustentabilidade.

Palavras-chave: Percepção; Desenho; Educação Ambiental.

\footnotetext{
1Universidade Federal de Sergipe, Aracaju, SE. E-mail: felipesantosprof@hotmail.com 2Universidade Tiradentes, Aracaju, SE. E-mail: natalieckert_mma@hotmail.com 3Universidade Federal de Sergipe, Aracaju, SE. E-mail: rejanes_oliveira@hotmail.com ${ }^{4}$ Universidade Federal de Sergipe, Aracaju, SE. E-mail: leisi.tutora@yahoo.com.br.

5Universidade Tiradentes, Aracaju, SE. E-mail: andscoelho@yahoo.com.br
} 


\section{Introdução}

A prática da Educação Ambiental relaciona a teoria com a prática e deve buscar facilitar a compreensão das relações socioambientais na contemporaneidade. Sobre o papel do professor/educador ambiental, esse deve articular estratégias de ensino na promoção de uma educação crítica. Portanto, a Educação Ambiental deve estar entrelaçada em um trabalho pedagógico participativo, em que todos juntos comunguem dos mesmos objetivos a serem alcançados, contribuindo, assim, para a transformação da realidade, como sujeitos críticos e atuantes.

Para que isso seja possível, os professores precisam estar devidamente preparados e qualificados para trabalhar com seus alunos temas relevantes e atuais, para que os aprendizes compreendam o contexto à sua volta e possam desenvolver ações que os permitam se sentirem sujeitos proativos no meio socioambiental em que vivem, por meio da experiência direta e pessoal.

Observa-se, uma timidez científica sobre a definição de categorias que sirvam de referência para análise de percepção socioambiental através de desenhos. Portanto, a relevância científica e social do presente estudo é oferecer um embasamento teórico para discutir as categorias de percepção socioambiental, contribuir para um aprofundamento conceitual dos dilemas ambientais vivenciados pela sociedade contemporânea e permitir entender seu comportamento frente às constantes degradações socioambientais na atualidade.

Nesse sentido, este artigo entende que a percepção ambiental está ligada à construção histórica da formação do indivíduo no seu caminhar social, sendo que a sua inter-relação com o ambiente define seu modo de apropriação do mesmo. Logo, os desenhos podem elucidar as categorias de percepção ambiental dos seus interlocutores, permitindo um (re)pensar sobre a ótica de comportamento desses indivíduos sobre a natureza, em uma atitude social, ambiental e econômica mais sustentável.

Conhecer a percepção ambiental é de fundamental importância para desvelar a relação que o indivíduo estabelece com o meio ambiente. Mas como seria possível alcançar esse conhecimento? Como a análise de desenhos permitiria o desenvolvimento de categorias de percepções ambientais de diferentes interlocutores? Que contribuições a análise dessas categorias poderia trazer para se entender a relação sociedade/natureza de um grupo? Essa discussão seria factível para o debate em Educação Ambiental, pelos pesquisadores da área?

Por entender a dificuldade de se trabalhar uma Educação Ambiental relevante, este artigo objetivou descrever uma metodologia de análise de desenhos para compreender a percepção dos indivíduos e suas relações com o meio ambiente. Para atingir tal objetivo, buscou se alcançarem as seguintes metas: analisar as percepções socioambientais de participantes de cursos de extensão universitária em Educação Ambiental; categorizar desenhos socioambientais, levando em conta a frequência de fenômenos e a similaridade 
dos desenhos desses participantes; e discutir a relação sociedade/natureza contida nos desenhos analisados.

\section{A formação do professor para a prática da educação ambiental}

A visão socioambiental orienta-se por uma racionalidade complexa e interdisciplinar e pensa o meio ambiente não como um campo de interações entre a cultura, a sociedade e a base física e biológica dos processos vitais, no qual todos os termos dessa relação se modificam dinâmica e mutuamente. [...] Assim, para o olhar socioambiental, as modificações resultantes da interação entre os seres humanos e a natureza nem sempre são nefastas; podem muitas vezes ser sustentáveis, propiciando, não raro, um aumento da biodiversidade pelo tipo de ação humana ali exercida (CARVALHO, 2004, p.37).

Na sociedade contemporânea, a presença de indivíduos responsáveis e conscientes de suas ações vem se tornando cada vez mais decisiva, uma vez que os mesmos assumem papéis indispensáveis na construção e formação de outras pessoas, para que essas possam atuar no meio social de modo crítico e reflexivo e possam exercer a sua cidadania.

Dispor e agir de modo sustentável tornou-se necessário no século $\mathrm{XXI}$, pois as pessoas devem, com urgência, modificar seus posicionamentos, para que as gerações futuras possam contemplar o encanto da natureza e desfrutar dela com qualidade e em harmonia com todos os seres vivos (DIAS, 2007). Por isso, as pessoas precisam se conscientizar da necessidade de conservação do meio ambiente, e isso implica a sensibilização. Assim sendo, a educação se torna crucial nesse contexto, em que o professor deve contribuir para que os alunos tenham percepção da importância de viver em uma sociedade ecologicamente humana e sustentável.

Para tanto,

é desejável a criação, por nós educadores, de um ambiente educativo que propicie a oportunidade de conhecer, sentir, experimentar; ou seja, vivenciar aspectos outros aos que predominam na constituição da atual realidade socioambiental. Isso poderá potencializar uma prática diferenciada que, pelo incentivo à ação cidadã em sua dimensão política, repercuta em novas práticas sociais voltadas para a sustentabilidade socioambiental (BRASIL, 2000, p.91).

Nesse sentido, o professor torna-se uma peça fundamental na construção de uma sociedade mais justa e democrática, porque o mesmo proporciona instrumentos necessários para que os alunos se sintam engajados na luta por um mundo melhor. Vale ressaltar que o professor precisa passar por uma formação que o subsidie a desenvolver uma prática interdisciplinar, 
que, para Morin (2000), é um modo que viabiliza aprender nas relações entre as áreas do conhecimento e nas relações interpessoais, visto que é o ponto de partida no qual se assegura a necessidade de formar pessoas capazes de enfrentar os dilemas do seu tempo.

Segundo Munhoz (2004), uma das formas de levar Educação Ambiental à comunidade é pela ação direta do professor, na sala de aula e em atividades extracurriculares. Por meio de atividades como leitura, trabalhos escolares (reciclagem), visitas técnicas, pesquisas e debates, os alunos poderão entender os problemas que afetam a comunidade onde vivem, ser solicitados a refletir e criticar as ações de desrespeito ao meio ambiente e entender que a riqueza natural nele contido é patrimônio de todos os que nele habitam.

Partindo desse pressuposto, os professores são elementos-chave no processo de conscientização dos alunos frente às dificuldades ambientais e, ao mesmo tempo, irão incentivar em seus alunos hábitos e atitudes concretas de proteção ambiental e respeito à natureza, transformando-os em cidadãos conscientes e comprometidos com o futuro do país (TRISTÃO, 2008).

Com isso, é essencial apresentar aos alunos várias experiências, com a intencionalidade de ampliar sua visão, para que eles possam se inserir em diversas situações de preservação dos recursos naturais e tenham uma percepção contextualizada com a realidade, contribuindo, então, para o empoderamento do senso crítico.

As ações de educadores ambientais devem propor a criação e promover a ocupação de espaços possíveis, onde os princípios participativos possam se expressar na perspectiva construtivista de novos saberes e práticas que estimulem a organização coletiva e espaços colaborativos de ruptura da armadilha paradigmática. Como, por exemplo, a construção participativa do projeto político-pedagógico da escola; a constituição de grêmios estudantis; associações de pais e mestres; conselhos escolares/comunidade; COM-VIDAS; implantação de agendas 21 escolares e comunitárias (BRASIL, 1997, p. 92).

Além de o professor ter um papel expressivo no processo de desenvolvimento dos alunos, é relevante observar que ainda não se dá o devido valor às suas ações; ficando cada vez mais difícil efetivar uma educação que priorize a formação integral do aluno. "[...] é fundamental capacitar cientificamente o professor sobre como inserir as questões ambientais em suas aulas, pois o educador poderá tornar-se o agente promotor da Educação Ambiental reflexiva, calcada num trabalho contínuo e permanente" (SANTOS; PARDO, 2011, p.83-84).

Nesse sentido, a capacitação do professor deverá contribuir na promoção de instrumentos para lidar com as diferentes e diversas posturas dos alunos frente à conservação da natureza. Entretanto, percebe-se a incipiente formação dos alunos quanto à conservação do meio ambiente. Na maioria das

revista brasileira educação ambiental 
vezes, a escola não tem uma proposta pedagógica voltada para a execução de projetos que posicionem os alunos numa visão crítica quanto à sustentabilidade e ao uso adequado dos recursos naturais (VASCONCELOS, 2008). Isso acontece pela ausência de uma preparação por parte da escola e dos professores, que, em alguns casos, ficam atrelados apenas às informações dos livros didáticos e não buscam metodologias concretas para contextualizarem com a realidade dos alunos (FELIZOLA, 2007).

A prática da Educação Ambiental parte da iniciativa de se relacionar a teoria com a prática, e isso deve levar os professores a fazerem parte de uma educação continuada, que facilita a compreensão dos dilemas contemporâneos para que possam articular estratégias de ensino na promoção de uma educação de qualidade. Para tanto, a Educação Ambiental deve estar entrelaçada em um trabalho pedagógico participativo, em que todos juntos comunguem dos mesmos objetivos a serem alcançados, contribuindo, assim, para a transformação da realidade, como sujeitos críticos e atuantes. Vale ressaltar que, segundo o Parâmetro Curricular Nacional de Meio Ambiente (PCN), "[...] o professor precisará conhecer mais amplamente os conceitos e os procedimentos da área para poder abordá-los de modo adequado" (BRASIL, 1997, p.77).

Nessa perspectiva, para mediar um ensino que contemple ações pedagógicas que permitam aos alunos relacionar suas atitudes cotidianas com a conservação ambiental, o professor deve partir de uma formação inicial e continuada Brasil (1997). Para isso, é fundamental ampliar as interconexões de união com outras instituições de ensino, visto que, atualmente, muitas delas negligenciam seu papel na oferta de cursos para formar professores ambientais (FELIZOLA, 2007; TRISTÃO, 2008; SANTOS; PARDO, 2011).

Além de uma formação inicial consistente, é preciso considerar um investimento educativo contínuo e sistemático para que o professor se desenvolva como profissional de educação. [...] A formação não pode ser tratada como um acúmulo de cursos e técnicas, mas sim como um processo reflexivo e crítico sobre a prática educativa. Investir no desenvolvimento profissional dos professores é também intervir em suas reais condições de trabalho (BRASIL, 2000, p. 30).

Está claro, portanto, que os professores precisam estar devidamente preparados e qualificados para trabalharem com seus alunos temas relevantes e atuais, para que os discentes compreendam o contexto à sua volta quando interagem e desenvolvem ações que os levem a se sentirem sujeitos proativos no meio social em que vivem, por meio da experiência direta e pessoal.

Nesse sentido, uma das alternativas que as escolas devem buscar é a elaboração de projetos pedagógicos para promover o enfrentamento das fragilidades com que elas se deparam (SANTOS, 2012). E os professores precisam assumir seu verdadeiro papel, para articularem estratégias na Revbea, São Paulo, V. 12, № 2: 156-177, 2017. 
promoção de uma educação de qualidade. Na visão de Sorrentino (1998), o maior desafio para os educadores ambientais é resgatar e desenvolver valores e comportamentos como confiança, respeito mútuo, responsabilidade, solidariedade em uma sociedade em que o ter está valendo mais do que o ser.

É preciso ainda que se estimule uma visão global e crítica das questões ambientais, que se faça o indivíduo compreender os efeitos da degradação e se consiga reivindicar ações políticas para solucioná-las, seja em nível local ou mesmo global (DIAS, 1992). Com o objetivo de trabalhar, no contexto escolar, problemas ambientais locais, bem como os globais, o professor deve partir da realização de uma prática que proporcione aos alunos o desenvolvimento da cidadania, a percepção de que é possível melhorar e transformar o ambiente (SANTOS, 2012).

Para tanto, uma verdadeira Educação Ambiental busca satisfazer os direitos civis, econômicos, sociais, espirituais e culturais das populações. É exatamente isso que deve vigorar para a sociedade alcançar a sonhada sustentabilidade, que exige modificações equilibradas do ponto de vista ético, ecológico, econômico, social e ambiental (SANTOS; PARDO, 2011, p.57).

É necessário que os alunos participem e se conscientizem como responsáveis pelos resultados concretos a serem adquiridos - a exemplo da coleta seletiva do lixo: a importância de reduzir, reciclar e reutilizar. Desenvolver um conhecimento mais amplo dos alunos e convidá-los a olharem criticamente para seu entorno, para estabelecerem objetivos e encontrarem soluções para os problemas ambientais (GUIMARÃES, 1995). Desse modo, Santos e Pardo (2011, p.34) afirma que "uma boa prática de Educação Ambiental deve conduzir o indivíduo ao conhecimento da problemática socioambiental'.

Para a condução viável da prática ambiental, é de fundamental importância a existência de professores que pesquisem a melhor proposta pedagógica, que busquem possibilidades e sugestões e que permitam a abertura de discussões que envolvem os problemas socioambientais. Assim, os alunos construirão uma reflexão sobre a importância de uma relação social mais justa e equilibrada (MUNHOZ, 2004; SANTOS, 2012). Portanto, o professor tem, como papel central, possibilitar o diálogo, a conversação e a socialização dos saberes com os alunos, para trocar conhecimentos e experiências. Juntos eles construirão novos significados e, consequentemente, uma sociedade mais ecologicamente sustentável, com melhores condições e oportunidades de atuar criticamente no meio social. 


\section{Consciência perceptiva de natureza: a visão do indivíduo sobre sua relação com a natureza}

Percepção ambiental pode ser definida como sendo uma tomada de consciência do ambiente pelo homem, sendo o ato de perceber o ambiente em que se está inserido. A percepção pode estar diretamente ligada à construção histórica da formação do indivíduo no seu caminhar social e ode representar, em relação ao ambiente, um aprender a proteger, valorizar e cuidar do meio que o cerca.

Ribeiro (2003) expõe que o primeiro contato que o indivíduo mantém com o ambiente que o cerca é através da sensação captada pelos órgãos dos sentidos. Sendo que esses sentidos levam à percepção, que, por sua vez, é responsável pela formação de imagens mentais desse ambiente.

Oliveira (2002) define qualquer meio ambiente conforme a percepção que cada sujeito faz da realidade que o cerca. Assim, este trabalho leva em conta e conceitua percepção enquanto algo que parte das aptidões construídas culturalmente no decorrer da vivência histórica dos indivíduos. Trata-se de uma dimensão que é subjetiva, mas, ao mesmo tempo, segue padrões de significados, uma vez que é construída culturalmente, através da relação da sociedade com a natureza.

Cada sociedade percebe, reage e responde diferentemente às ações sobre o ambiente em que vive (FERNANDES et al., 2015). As respostas ou manifestações daí decorrentes são resultado das percepções (individuais e coletivas), dos processos cognitivos, julgamentos e expectativas de cada pessoa. Dessa forma, o estudo da percepção ambiental é de fundamental importância para que se possa compreender melhor as inter-relações entre o homem e o ambiente, suas expectativas, anseios, satisfações e insatisfações, julgamentos e condutas. $E$, além de tudo, a percepção pode direcionar a relação que esse indivíduo ou sociedade estabelece com o meio natural em que vive, sendo essa relação, de aproximação ou mesmo de afastamento (SANTOS, 2012).

Em tempos remotos, não havia a conscientização de que a matériaprima poderia se extinguir. A percepção dominante se caracterizava pelo pensamento progressista da natureza, o qual acreditava que a natureza sempre se renovaria e assim daria continuidade àquela prática de exploração dos recursos, seja ela necessária ou não. Entretanto, devido às devastações desenfreadas e à notável perda dos ecossistemas, foi se percebendo o abuso que a natureza vem sofrendo em prol do crescimento econômico. Isso porque os recursos naturais, em sua maioria, não são renováveis e, para se poder continuar a usufruir dos benefícios naturais, se faz necessária uma ruptura com o referido antigo modo de pensar (LEFF, 2001; DIAS, 2007; VASCONCELOS, 2008; SANTOS e Pardo, 2011). 
Seguindo esse pensamento, conciliar a produção de bens com a preservação ambiental é uma atitude fundamental a ser tomada em benefício das gerações futuras, que terão que pagar um alto preço para saldar a dívida ambiental e conseguir uma qualidade de vida aceitável (MEC, 2016, s.p.).

Buscar uma visão mais sistêmica e sustentável, ou seja, uma ação mais racional na relação homem e natureza é uma necessidade contemporânea. Interceder criticamente sobre determinadas percepções é também importante, pois, mesmo sem perceber, o indivíduo pode perpetuar em seu cognitivo uma percepção em que ele se vê fora da natureza e, desse modo, sua relação com esse meio se encontra desconectada (LEFF, 2001; PORTO-GONÇALVES, 2006). É necessário, portanto, conhecer as percepções para direcionar novos caminhos de relações entre o indivíduo e a coletividade com o meio, pois perceber adequadamente natureza é uma necessidade socioambiental.

Desta forma, o estudo da percepção ambiental é de fundamental importância para que possamos compreender melhor as inter-relações entre o homem e o ambiente, suas expectativas, anseios, satisfações e insatisfações, julgamentos e condutas (FERNANDES et al., 2015, p.1).

Devido à crescente preocupação com o meio natural, é de suma importância criar mecanismos metodológicos para conhecer as percepções que o indivíduo possui em relação ao meio que o cerca. Isso porque, diagnosticando determinada percepção, pode-se trabalhar para buscar uma maior racionalidade de entendimento da relação sociedade/natureza, uma melhor percepção que possa efetivar saberes e entendimentos pautados no racionalismo da sustentabilidade.

\section{Metodologia da pesquisa}

A metodologia da pesquisa adaptou o método de análise de conteúdo, descrito por Bardin (2006). Foram criadas categorias de análise de desenhos, a partir de ilustrações feitas por participantes de cursos de extensão ofertados pelos autores que discutiam a relação entre o homem e a natureza e o importante papel da Educação Ambiental para a efetivação de comportamentos pró-ambientais. As atividades de extensão foram realizadas em eventos científicos na Universidade Tiradentes e na Universidade Federal de Sergipe, no ano de 2015.

Tal proposta de pesquisa foi inserida nesses eventos porque os grupos que os organizaram entendiam o papel importante da discussão sobre Educação Ambiental na formação de seus licenciados. Objetivavam, desse modo, contemplar a práxis existente na Educação Ambiental enquanto promotora de valores e comportamentos socioambientais.

revista brasileira educação ambiental 
A presente pesquisa utilizou um método qualitativo, pois, como afirmam Marconi e Lakatos (2010), esse método possui o mínimo de estruturação prévia. Entende-se que, para o seu trato e rigor científico, as teorias aplicáveis foram empregadas no decorrer da investigação.

A metodologia qualitativa preocupa-se em analisar e interpretar aspectos mais profundos, descrevendo a complexidade do comportamento humano. Fornece análise mais detalhada sobre as investigações, hábitos, atitudes, tendências de comportamento etc (MARCONI; LAKATOS, 2010, p.270).

Esta investigação se caracteriza também como exploratória, pois aborda um tema pouco estudado: descreve uma metodologia de análise de desenhos para compreender a percepção dos indivíduos e suas relações com o meio ambiente. Para Gil, uma pesquisa tem caráter exploratório no momento em que o pesquisador tem como objetivo descrever melhor o problema, pois "trata-se de abordagem adotada para a busca de maiores informações sobre determinado assunto" (2006, p.41). Esse tipo de pesquisa possui também um planejamento flexível e é indicado quando há pouco conhecimento sistematizado sobre o assunto.

O estudo se enquadra, ainda, na metodologia descritiva, pois a pesquisa procura abranger aspectos variados de um contexto social, no caso a percepção socioambiental através de desenhos. Também busca explicação acerca de relações entre fenômenos à medida que analisa a opinião dos participantes sobre a interpretação de seus desenhos e a relação entre sociedade e natureza.

O enunciado principal, para que os participantes realizassem o desenho, foi: Desenhe qual é o seu conceito de natureza. Algumas orientações foram dadas, entre elas, a de que o desenho não precisaria ser identificado e que evitassem perguntar, ou mesmo olhar, desenhos de outros participantes. Essa explicação foi bastante explicitada para que não houvesse influência na percepção do indivíduo ao observar o desenho produzido pelo colega.

Para analisar esses desenhos, foi adaptada a metodologia de análise de conteúdo descrita por Bardin (2006), em que se busca a essência das similaridades de frases escritas ou faladas pelos participantes; e uma adaptação de Santos e Pardo (2011), pela qual, a partir das similaridades, são elaboradas categorias que reúnem os pontos principais do discurso escrito ou dito pelos sujeitos da pesquisa.

A análise de conteúdo é um processo pelo qual se pode compreender a realidade, por meio da interpretação de textos ou discursos que tenham vínculos com essa mesma realidade. Assim, esse método possui um respaldo científico para se extrair o conteúdo central de textos, geralmente escritos, ou de discursos. 
Diferentemente do material proposto por Bardin (2006), as categorias de análise foram criadas a partir da observação dos desenhos. Os detalhes representados pelos participantes foram analisados e discutidos em cada atividade, com os participantes, para validar as categorias criadas, buscandose, ao máximo, a fidedignidade perceptiva.

O método de análise de conteúdo de Bardin (2006) extrai, do texto escrito, a palavra-chave que representa o posicionamento de um indivíduo. Desse modo, optou-se por adequar esse método ao desenho porque a representação de similaridades permitiu que cada desenho pudesse ser enquadrado nas categorias formuladas para esta pesquisa.

A análise de conteúdo constitui-se de um conjunto de técnicas e instrumentos empregados na fase de análise e interpretação de dados de uma pesquisa, aplicando-se, de modo especial, ao exame de documentos escritos, discursos, dados de comunicação e semelhantes, com a finalidade de uma leitura crítica e aprofundada, levando à descrição e interpretação destes materiais, assim como inferências sobre suas condições de produção e recepção (MORAES, 1994, p.104).

Desse modo, para encontrar a percepção socioambiental, os desenhos foram analisados, observando-se as similaridades e a presença de determinados fenômenos, como explicitado no quadro de interpretação das categorias de percepção. Posteriormente, os desenhos foram enquadrados nas respectivas categorias de percepção. Sendo assim, as percepções são resultado das interfaces desenhos-similaridades-categorias metodológicas (Figura 1).

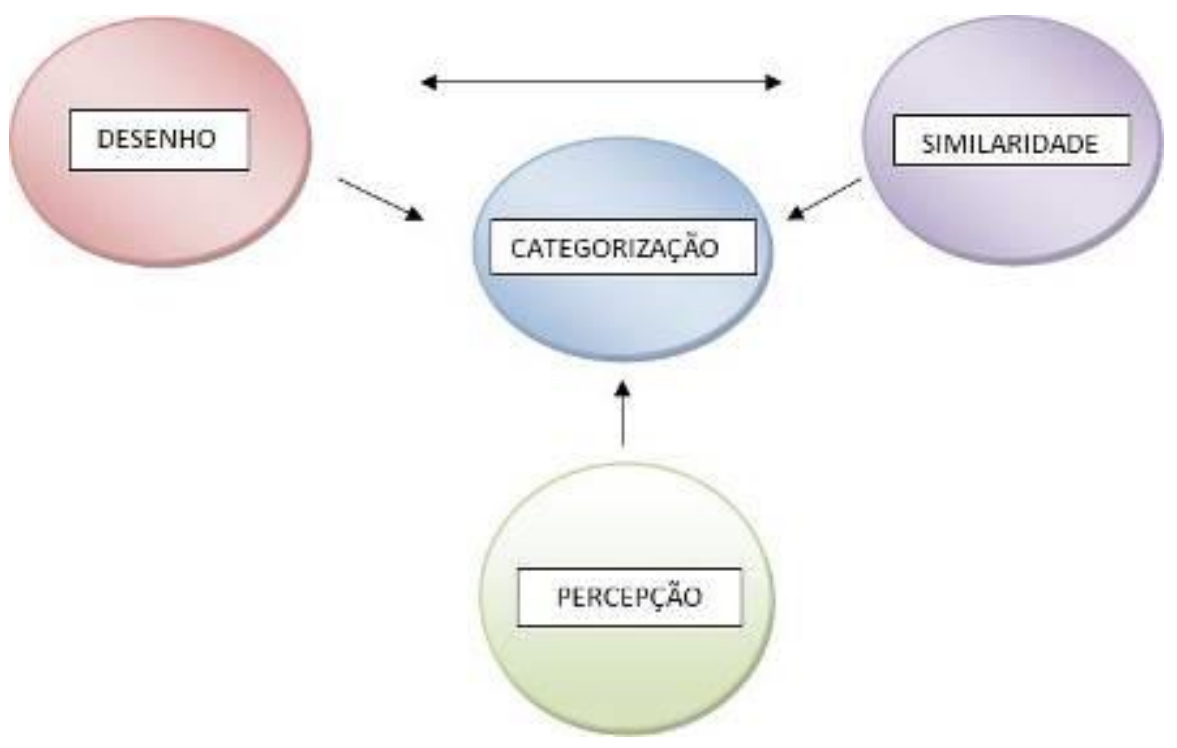

Figura 1: Metodologia aplicada aos desenhos. 


\section{Resultado e discussão}

Esta pesquisa contou com 50 participantes, com um desenho por pessoa, obtendo um total de 50 desenhos, elaborados durante duas atividades de extensão. O resultado da análise do corpus da pesquisa resultou na criação de quatro categorias de percepções: Percepção Romântica, Percepção Negativa, Percepção de Dominação e Percepção de Sustentabilidade. Essas categorias representam, de forma teórica, a percepção da relação indivíduo/natureza. Através dessa metodologia, pode agrupar por similaridade essas percepções, contribuindo para o entendimento de sensações, entendimentos e percepções dos indivíduos em sua inter-relação com o espaço vivido e apropriado pelos mesmos.

Essas categorias, assim como suas características metodológicas, ou seja, as similaridades percebidas nos desenhos elaborados, são apresentadas no Quadro 1, a seguir:

Quadro 1: Interpretação das categorias de percepção criadas a partir de desenhos.

\begin{tabular}{|c|c|c|c|}
\hline $\begin{array}{l}\text { Percepção } \\
\text { Romântica }\end{array}$ & $\begin{array}{l}\text { Percepção } \\
\text { Pessimista }\end{array}$ & $\begin{array}{l}\text { Percepção } \\
\text { Dominação }\end{array}$ & $\begin{array}{l}\text { Percepção } \\
\text { Sustentabilidade }\end{array}$ \\
\hline $\begin{array}{lr}\text { Presença total da } \\
\text { natureza física. Os } \\
\text { elementos dessa } \\
\text { percepção são } \\
\text { representados pela } \\
\text { natureza r bela, } \\
\text { como a natureza } \\
\text { intocada r pelo } \\
\text { homem, } \\
\text { natureza frutífera e } \\
\text { perfeita. }\end{array}$ & $\begin{array}{l}\text { Apresenta } r \\
\text { degradação do } \\
\text { meio fortemente } \\
\text { representada pela } \\
\text { ação humana. } \\
\text { Aborda traços } \\
\text { sobre a poluição } \\
\text { hídrica, do ar e do } \\
\text { solo. A maior } \\
\text { expressão desses } \\
\text { desenhos está na } \\
\text { degradação do } \\
\text { espaço } \\
\text { representado. }\end{array}$ & $\begin{array}{l}\text { Apresenta } \\
\text { predominância dos } \\
\text { elementos } \\
\text { construídos pelos } \\
\text { seres humanos, se } \\
\text { comparados aos da } \\
\text { natureza física. Nota- } \\
\text { se uma expressiva } \\
\text { quantidade de casas, } \\
\text { ruas, prédios, } \\
\text { avenidas, em } \\
\text { detrimento da } \\
\text { presença de áreas } \\
\text { verdes de outros } \\
\text { animais. }\end{array}$ & $\begin{array}{l}\text { Apresenta, no desenho, } \\
\text { fenômenos } \\
\text { demonstram a inter- } \\
\text { relação necessária entre } \\
\text { o homem e a natureza. } \\
\text { Foca a troca de energia } \\
\text { existente entre as } \\
\text { diferentes camadas do } \\
\text { planeta Terra, a } \\
\text { necessidade do homem } \\
\text { quanto aos recursos } \\
\text { naturais e a } \\
\text { preservação/con- } \\
\text { servação destes. }\end{array}$ \\
\hline
\end{tabular}

Após a criação das categorias de percepção, os desenhos foram reavaliados, catalogados e passaram a integrar uma ou mais categorias expostas acima. Desse modo, as percepções também puderam ser quantificadas, contribuindo para uma discussão mais ampla sobre a percepção ambiental através de desenhos.

A Figura 2 mostra o número de desenhos e sua inserção nas percepções definidas na pesquisa. Este gráfico foi produzido levando-se em conta a explicação do desenho pelo participante, na atividade de extensão. 


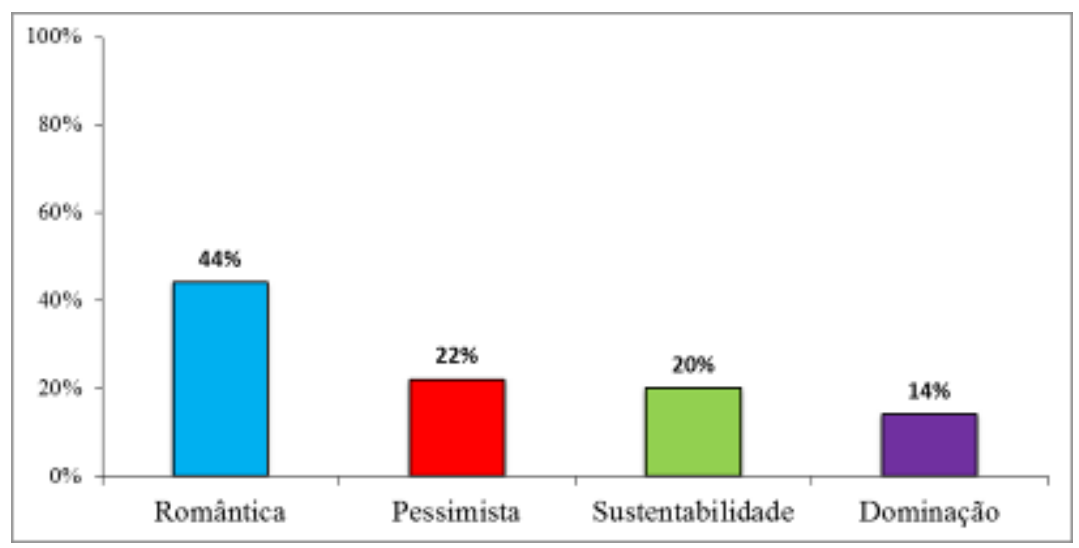

Figura 2: Enquadramento dos desenhos dos participantes nas quatro categorias criadas.

Cerca de $44 \%$ das percepções dos participantes do curso de extensão enquadrou-se na categoria romântica de natureza, aquela em que permeia a ideia de que a natureza permanece bela e intocada. Já $22 \%$ dos participantes tiveram suas percepções enquadradas na categoria pessimista; foi notória, nesses desenhos, a presença expressiva de degradação ambiental.

Cerca de $20 \%$ dos participantes tiveram suas percepções enquadradas na categoria sustentabilidade, aquela que busca uma relação de conservação do meio ambiente pelo homem, que busca uma relação mais equilibrada do processo de usufruto da natureza pela humanidade. A categoria dominação obteve a menor porcentagem de representação no grupo de realização da pesquisa; cerca de $14 \%$ dos participantes desenharam um ambiente fortemente representado pela construção humana, ficando em evidência um ambiente construído pela técnica.

No grupo estudado, está o participante 15, aluno de licenciatura em Ciências Biológicas, que frequentou o curso de extensão com o objetivo de trabalhar jogos e brincadeiras para a Educação Ambiental. No desenho desse aluno, observa-se, claramente, a forte presença de elementos da natureza física, perfeita e bela. Por conter essas características, esse desenho foi enquadrado na categoria de percepção romântica (Figura 3).

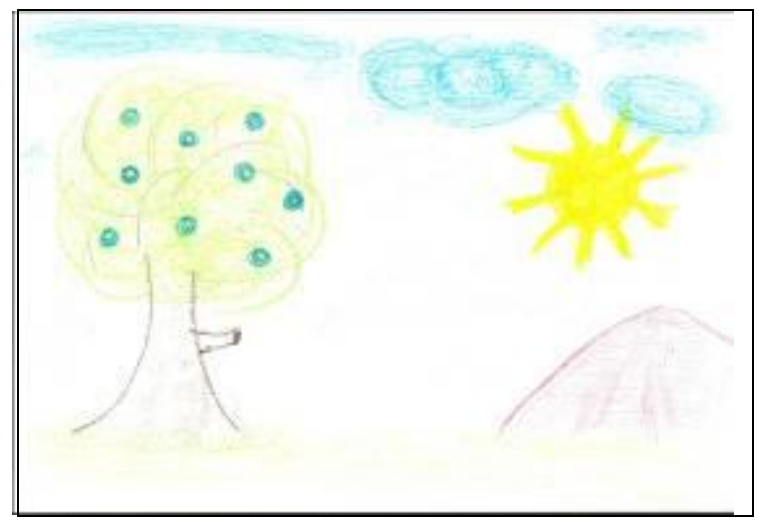

Figura 3: Desenho do participante 15 representando uma Percepção Romântica da Natureza. 


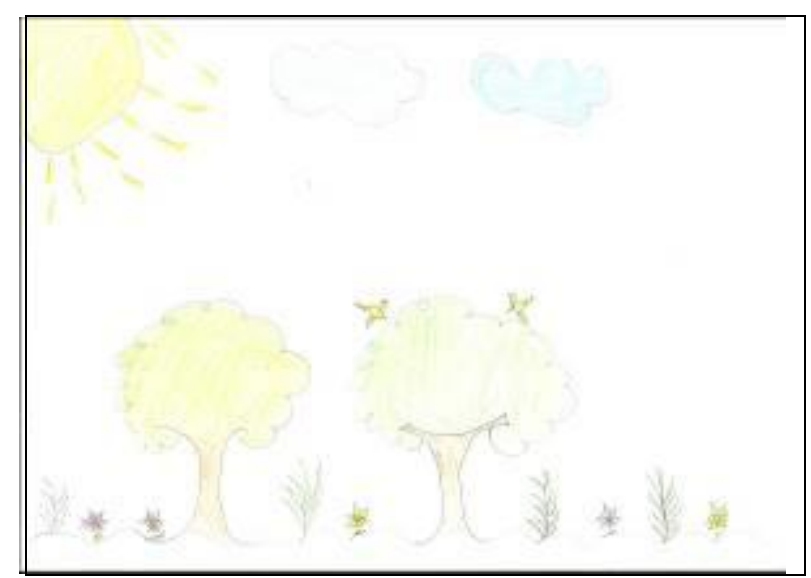

Figura 4: Desenho do participante 40 representando uma Percepção Romântica da Natureza.

Essa categoria ainda permite abordar dois excertos, o primeiro, em que o homem não se vê natureza; por isso o indivíduo desenha e não agrega a presença do homem em sua representação. Outro insere a percepção de que a natureza, por si só, irá conseguir se regenerar, o que caracteriza uma percepção romântica sobre a perfeição e a força de regeneração do meio ambiente. Observa-se resultado similar com a categoria de análise posta por Teles: "Uma visão harmônica da natureza, o belo, o equilibrado, o intocável. Aqueles ambientes que se formaram sem intervenção humana" (2016, p. 35).

Em um segundo momento, esse autor também aborda razões para o afastamento do homem em relação à natureza. Para ele, a sociedade capitalista passou a definir natureza como tudo que se opõe a cultura. A cultura passa, portanto, a ser entendida como algo superior à natureza, e cabe à humanidade controlar e dominar a mesma. Desse modo, Porto-Gonçalves expõe que "chama-se de selvagem aquele que se encontra no polo oposto da cultura. E, note bem, selvagem quer dizer da selva, mais uma vez, do plano da natureza". (2006, p. 24).

Garrido e Meirelles (2016) encontrou, em seu resultado de pesquisa, convergência com essa categoria. Ela trabalhou, com alunos do Ensino Fundamental, as representações por desenhos e as falas dos alunos a respeito dos seus desenhos. Esses alunos trilharam, na maioria das vezes, uma percepção naturalista, que, segundo a autora, se encontra desligada dos contextos social, econômico, político e cultural que permeiam a sociedade.

Outra categoria descrita no presente trabalho é a percepção pessimista. Ela é caracterizada pela forte presença de elementos de degradação e essa é resultante da relação humana. Se a percepção romântica não deixa visíveis as ações humanas, a pessimista expõe a visão de um ambiente em crise, insustentável, compreendendo a relação de degradação que o homem estabelece com o meio.

Percebe-se que o Desenho 5 expõe 0 ato de degradação presente em diferentes paisagens naturais. Apesar de não conter o homem explicitamente desenhado, a construção e/ou a presença da indústria o torna subentendido. 
Existem, portanto, fortemente presentes nessas categorias, ações de degradação do meio, estando interligadas à insustentabilidade da relação homem/natureza.

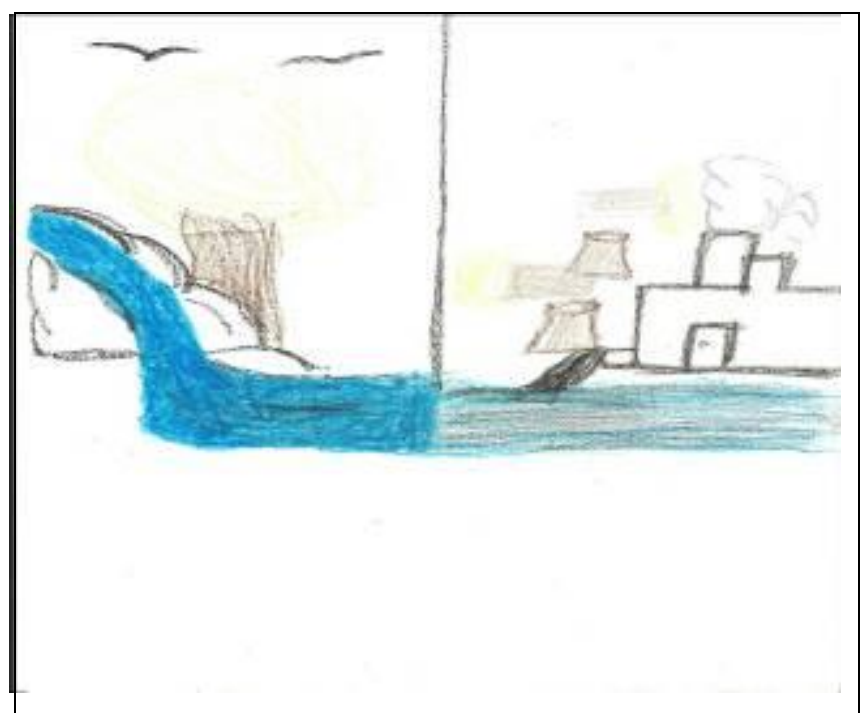

Figura 5. Desenho do participante 4 representando uma Percepção Pessimista da Natureza.

O trabalho desenvolvido por Aguiar e Pereira (2016), com crianças e adolescentes entre 11 e 17 anos, identificou dois grupos de representação da relação homem e natureza, através de desenhos. O primeiro grupo analisado pelo autor percebeu uma relação conflitante do homem com a natureza. As representações dos desenhos trazem, de forma expressiva, práticas dos seres humanos causando alterações ao meio ambiente, de modo prejudicial. Aguiar e Pereira afirmam que, "para esses estudantes, a presença do homem acaba gerando impactos negativos ao meio ambiente" (2016, p.1).

Todos os desenhos apresentam o descarte de lixo de maneira incorreta; ação responsável por diversos danos ao meio ambiente, uma vez que o acúmulo de lixo em um curso d'água além de causar transtornos ao próprio ser humano, pode dizimar espécies viventes naquele local (AGUIAR; PEREIRA, 2016, p.1).

A percepção de dominação indica a presença de construções humanas na própria relação dos elementos físicos da natureza. Isso também se respalda em um ambiente equilibrado, pois não demonstra fortemente a degradação ambiental. Nessa percepção, estão destacados os espaços construídos pela atividade humana. A maior expressão dessa percepção esta em desenhos que representam o ambiente humano, suas diversidades arquitetônicas e de modais de comunicação e transporte (Figura 6). 


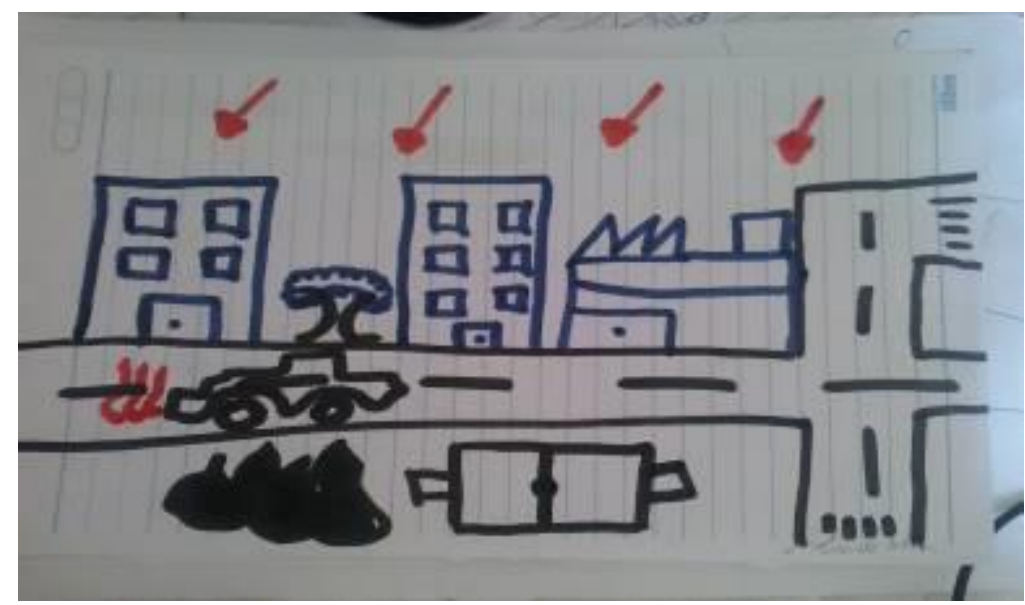

Figura 6: Desenho do participante 25 representando uma Percepção Dominação da Natureza.

Figura 7: Desenho do participante 7 representando uma Percepção Dominação da Natureza. forma:

O participante 16, aluno do curso de Pedagogia, descreve da seguinte

P 16: "Tudo que é construído pelo homem faz parte da natureza. Pois permite ao mesmo viver melhor".

P 21: "Entendo natureza como tudo que foi transformado em favor no ambiente social".

Cerca de $14 \%$ dos desenhos dos participantes da pesquisa foram enquadrados na categoria dominação. Assim como na pesquisa de Garrido e Meirelles (2016), nesses desenhos, foram encontrados, em maior quantidade, elementos produzidos pelos seres humanos, como ruas, prédios, casas etc. Sua pesquisa ocupou em descrever os elementos representados nos desenhos das crianças e sua finalidade era compreender a ligação entre o meio ambiente e os alunos. Ela trabalhou com a análise de duas categorias existentes nos Parâmetros Curriculares Nacionais Meio Ambiente e Saúde - PCN (BRASIL, 1997).

Revbea, São Paulo, V. 12, № 2: 156-177, 2017. 
Segundo os autores, os Parâmetros fomentam duas categorias: os elementos naturais e os artificiais. Em seu trabalho encontraram forte presença de elementos naturais, o que, na presente pesquisa, pode se enquadrar na categoria romântica. Já os desenhos que apresentam maior quantidade de elementos artificiais, a exemplo dos Desenhos 6 e 7, podem ser deferidos na categoria de dominação.

A percepção, segundo Ribeiro (2003), é desenvolvida através dos sentidos, e essa característica a torna única, ou seja, será diferente de indivíduo para indivíduo. Segundo esse mesmo autor, os estímulos sensoriais são despertados e é o que distingue a forma como cada indivíduo compreende sua realidade vivenciada.

Desse modo, quando se pretende compreender a visão de mundo de um indivíduo, é necessário conhecer sua percepção, pois a mesma interage de modo significativo na atitude dele em seu ambiente. Ribeiro afirma que "a percepção interessa a diversas ciências, pois não se pode começar a entender a percepção humana do mundo se não compreender também algo sobre 0 mundo, como um conjunto de eventos físicos, naturais e humanos" (2003, p.49).

Assim, corroborando com o pensamento de Oliveira (2002) de que o meio ambiente, seja ele qual for, é definido conforme a percepção que cada sujeito tem da realidade que o cerca e que a percepção é fruto da construção cultural dos diferentes indivíduos.

Torna-se importante salientar que as Categorias de Análise devem permitir flexibilidade, tanto nos seus pressupostos como nos seus objetivos iniciais... torna-se um instrumento de aproximação da realidade ambiental estudada através dos desenhos, revelando assim, novos caminhos a percorrer, novas possibilidades de interpretação (ANTONIO; GUIMARÃES, 2016, p.1).

A quarta percepção busca a racionalidade da interface homem/natureza. Encontra-se fortemente alicerçada na ideia de sustentabilidade ambiental, na simbiose existente na cadeia da vida e na necessidade do homem se ver na natureza e optar por uma nova conduta socioambiental, conduta que privilegia a ética, o valor e a equidade social.

O participante 18, aluno do curso de Ciências Biológicas, representou, no seu desenho a categoria de sustentabilidade. Esse desenho deixa explícita a interação que existe entre os elementos que compõem a biosfera, pois representa a troca de energia entre o ar, representado pelo sol, e pássaros; a hidrosfera e a litosfera; integrando o homem e os outros animais no sistema; e colocando ainda, no centro do ciclo em destaque, a compreensão de que é essa inter-relação que permite a vida (Figura 8). 


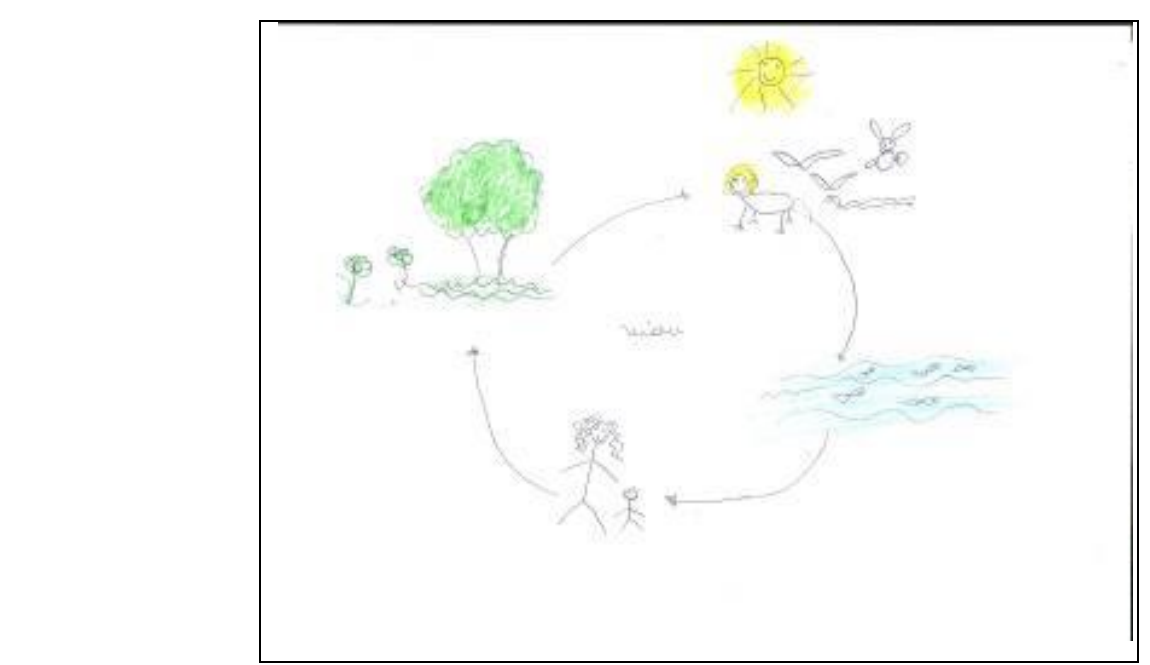

Figura 8: Desenho do participante 18 representando uma Percepção Sustentabilidade da Natureza.

Dois participantes, a seguir, fazem uma descrição a respeito das categorias romântica e de sustentabilidade, respectivamente:

P 11: "A natureza é o belo, o perfeito e o seguro, sem ela não existiria vida na terra".

$P$ 33: "A natureza é a nave mãe da fauna e flora do nosso perfeito planeta, a energia que existe entre eles necessita de atenção e de responsabilidade, uma vez que vivemos uma teia de relações".

A relação insustentável que a sociedade de consumo imprime sobre os recursos finitos da natureza vem ampliando os problemas socioambientais planetários. Isso vem exigindo que a sociedade passe a cogitar práxis mais sustentáveis, almejando novos atitudes e comportamentos pró-ambientais e que lute pela diminuição das desigualdades socioambientais que assolam parcela expressiva da sociedade, que vive em vulnerabilidade econômica e ambiental (SANTOS, 2012).

Os desequilíbrios ambientais causados pela falta de cuidado com o meio ambiente passaram a afetar direta e indiretamente uma grande parcela de seres humanos, visto que são parte do meio ambiente e dele não podem se dissociar. Hoje os impactos gerados por esta dissociação são também de ordem social, cabendo à sociedade uma mudança de comportamento e atitude em relação ao fato do homem não poder "ser conceituado sem o seu meio ambiente" (TELLES; ARRUDA, 2016, p. 1). 
Desse modo, a percepção de sustentabilidade corrobora com a visão de sustentabilidade proposta por Leff (2001). Ele defende que é necessária uma mudança nas formas de agir e pensar as questões e inter-relações socioambientais. Os indivíduos que possuem a percepção de sustentabilidade apresentam uma sensibilidade nítida a respeito da busca de uma relação de equidade entre natureza, ambiente e homem.

Atualmente o desafio de fortalecer uma educação ambiental convergente e multirreferencial é prioritário para viabilizar uma prática educativa que articule de forma incisiva a necessidade de se enfrentar concomitantemente a degradação ambiental e os problemas sociais (JABOBI, 2016, p.199).

Pode-se, assim, afirmar que a representação da percepção de sustentabilidade entende que os crescentes e complexos problemas ambientais apenas serão amenizados quando houver uma perpetuação dessa visão, que integraliza a simbiose entre a "cultura e a espécie homem" e a necessária "qualidade de gestão dos recursos naturais do planeta". Desse modo, é necessário efetivar novos e profícuos saberes, valores, comportamentos pró-ambientais (DIAS, 1992; GUIMARÃES, 1995; MUNHOZ, 2004).

Porto-Gonçalves (2006), em sua obra Os (des)caminhos do meio ambiente, também reflete sobre essa visão do homem fora da natureza. Primeiro, ele constrói uma crítica bastante incisiva sobre o próprio conceito de natureza. $\mathrm{O}$ autor diz que uma das maiores dificuldades para integrar 0 homem ao ambiente de modo sustentável, como a Educação Ambiental almeja, reside no próprio conceito de natureza. Isso porque, para determinados grupos, ela tem um valor meramente econômico (madeireira, mineradora etc.) e, para outros, um valor simbólico mais ecológico (geógrafo, biólogo, ecólogo etc.).

Nesse sentido, o conceito de natureza não é natural, sendo na verdade criado e instituído pelos homens. Constitui um dos pilares através do qual os homens erguem as suas relações sociais, sua produção material e espiritual, enfim, a sua cultura (PORTO-GONÇALVES, 2006, p. 23).

Observa-se essa relação de reciprocidade entre homem e ambiente nos Desenhos 8 e 9. É notória a dinâmica existente entre os seres humanos e sua interligação com o ambiente vivido. No Desenho 8 (acima), nota-se que as setas levam ao entendimento de troca de energia entre as camadas da biosfera e a necessidade humana de uso, de modo racional, dos recursos fornecidos pela natureza, interligando a produção econômica (agricultura, pesca) e a dinâmica do ambiente físico (chuvas, rios, ar, sol) e permitindo a qualidade de vida socioambiental. 


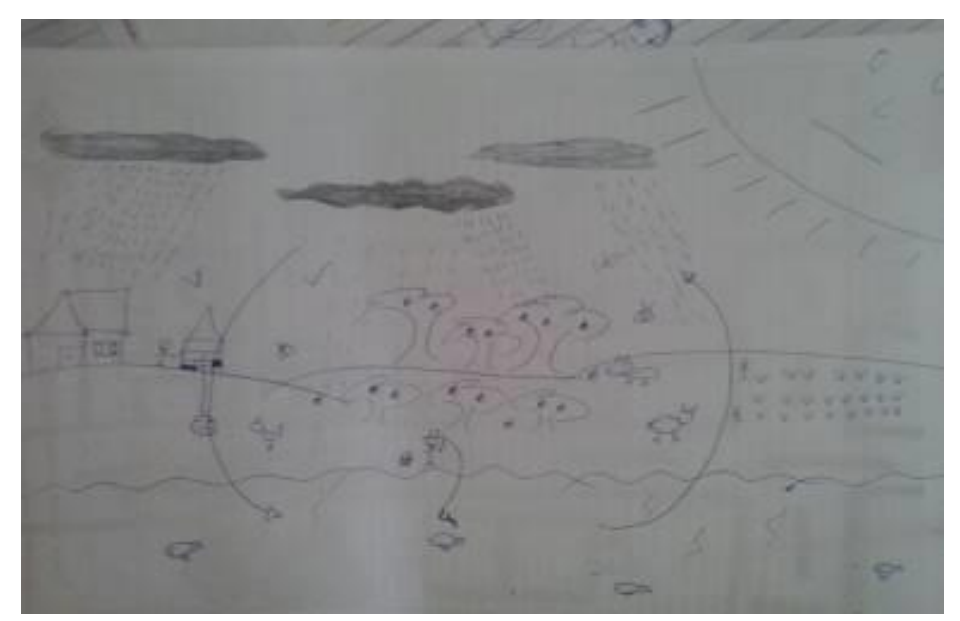

Figura 9: Desenho do participante 35 representando uma Percepção Dominação da Natureza.

Capra (2016) enquadraria esse desenho como sendo da ecologia profunda, pois se pode reconhecer nele a interdependência fundamental de todos os elementos, inclusive a presença do homem naquilo que o autor chama de "processos cíclicos da natureza".

O novo paradigma pode ser chamado de uma visão de mundo holística, que concebe o mundo como um todo integrado, e não como uma coleção de partes dissociadas. Pode também ser denominado visão ecológica, se o termo "ecológica" for empregado num sentido muito mais amplo e mais profundo que o usual (CAPRA, 2016, p. 16).

A pesquisadora Martha Tristão insere no debate a seguinte afirmação:

A relação entre meio ambiente e educação para a cidadania assume um papel cada vez mais desafiador, demandando a emergência de novos saberes para apreender processos sociais que se complexificam em riscos ambientais que se intensificam (2008, p. 20). 


\section{Conclusões}

Este trabalho contribui para um melhor entendimento da percepção ambiental de indivíduos sobre a natureza. A partir dessas constatações, é possível encontrar o melhor caminho para discutir e possibilitar a sensibilização ambiental, uma vez que, apesar de a percepção ser individual, ela pode ser alterada através da agregação de novos conceitos e de um novo olhar sobre o ambiente experimentado e vivido.

Após a análise das percepções ambientais do grupo estudado, constatase que o uso da metodologia de análise da percepção por desenhos permite direcionar os trabalhos e os debates socioambientais, contribuindo para uma busca de sensibilização ambiental. O presente trabalho mostra, ainda, que a metodologia de percepção pode, tranquilamente, ser usada em diferentes níveis de ensino, nas áreas formal e informal, que trabalham com a Educação Ambiental, como caminho para possibilitar uma reflexão sobre as questões socioambientais presentes na contemporaneidade.

\section{Referências}

AGUIAR, R.C.; PEREIRA, C.M.R.B. A educação ambiental em oficinas pedagógicas: reflexões a partir de desenhos. Disponível em: $<$ www.revistaea.org/artigo.php?idartigo=1970>. Acesso em: 28 jun. 2016.

ANTONIO, D.G.; GUIMARÃES, S.T.L. A representação do meio ambiente através do desenho infantil: refletindo sobre os procedimentos interpretativos. Disponível em: <www.revistaea.org/artigo.php?idartigo=343>. Acesso em: 28 jun. 2016.

BARDIN, L. Análise de conteúdo. Lisboa: Edições 70, 2006.

BRASIL. Secretaria de Educação Fundamental. Parâmetros Curriculares Nacionais: Meio Ambiente e Saúde. Secretaria de Educação Fundamental. Brasília, 1997.

BRASIL. Parâmetros Curriculares Nacionais: História e Geografia. Secretaria de Educação Fundamental. 2. ed. Rio de Janeiro: DP\&A, 2000.

CAPRA, F. A teia da vida: uma nova compreensão científica dos sistemas vivos. Disponível em: $<$ www.communita.com.br/assets/teiadavidafritjofcapra.pdf $>$. Acesso em: 20 jun. 2016.

CARVALHO, I.C.M. Educação ambiental: a formação do sujeito ecológico. São Paulo: Cortez, 2004.

DIAS, G.F. Educação ambiental: princípios e práticas. São Paulo: Gaiá, 1992.

DIAS, R. Gestão ambiental: responsabilidade social e sustentabilidade. 2. ed. São Paulo: Atlas, 2007.

FELIZOLA, M.P.M. Projetos de educação ambiental nas escolas municipais de Aracaju/SE. Dissertação de Mestrado. São Cristóvão, SE, 2007.

revista brasileira educação ambiental 
FERNANDES, R.S. et al. Uso da percepção ambiental como instrumento de gestão em aplicações ligadas às áreas educacional, social e ambiental. Disponível

em:

$<$ <ww.redeceas.esalq.usp.br/noticias/Percepcao Ambiental.pdf>. Acesso em: 14 maio 2015.

GARRIDO, L.S.; MEIRELLES, R.M.S. Percepção sobre meio ambiente por alunos das séries iniciais do Ensino Fundamental: considerações à luz de Marx e de Paulo. Disponível em: <http://www.scielo.br/pdf/ciedu/v20n3/15167313-ciedu-20-03-0671.pdf>. Acesso em: 12 jun. 2016.

GIL, A.C. Como elaborar projetos de pesquisa. 4. ed. reimp. São Paulo: Atlas, 2006.

GUIMARÃES, M. A dimensão ambiental na educação. Campinas: Papirus, 1995.

JACOBI, P. Educação ambiental, cidadania e sustentabilidade. Disponível em: <http://www.scielo.br/pdf/cp/n118/16834.pdf>. Acesso em: 22 jun 2016.

LEFF, E. Saber ambiental: sustentabilidade, racionalidade, complexidade, poder. Petrópolis, RJ: Vozes, 2001.

MARCONI, M.A.; LAKATOS, E.M. Metodologia científica. 5. ed. São Paulo: Atlas, 2010.

MEC - Ministério da Educação. Educação Profissional. Referenciais Curriculares de Educação Profissional: Meio Ambiente. 2000. Disponível em: <http://portal.mec.gov.br>. Acesso em: 29 mar. 2016.

MORAES, R. Análise de conteúdo: limites e possibilidades. In: ENGERS, M.E.A. (Org.). Paradigmas e metodologias de pesquisa em educação. Porto Alegre: EDIPUCRS, 1994.

MORIN, E. Os sete saberes necessários à educação do futuro. 2000.

MUNHOZ, T. Desenvolvimento sustentável e educação ambiental. Disponível em: $<$ http://emaberto.inep.gov.br/index.php/emaberto/article/view/1805/1776 >. Acesso em 2004.

OLIVEIRA, L. A percepção da qualidade ambiental. Caderno de Geografia, Belo Horizonte, v. 12, n. 18, p. 40-49, 1ํs sem. 2002.

PORTO-GONÇALVES, C.W. Os (des)caminhos do meio ambiente. 14. ed. São Paulo: Contexto, 2006.

RIBEIRO, L.M. O papel das representações sociais na educação ambiental. 2003. Dissertação (Mestrado em Educação) -. Pontifícia Universidade Católica. Rio de Janeiro, 2003.

SANTOS, F.A.S.; PARDO, M.B.L. Educação Ambiental: um caminho possível. Porto Alegre: Redes Editora, 2011. 
SANTOS, F.A.S.S. (Org.). Educação, saúde e meio ambiente. Percepções e perspectivas. Porto Alegre: Redes Editora, 2012.

SORRENTINO, M. A educação ambiental no Brasil. In: JACOBI, P. et al. (Orgs.). Educação, meio ambiente e cidadania: reflexões e experiências. São Paulo: SMA, 1998.

TELLES, A.; ARRUDA, M.P. O saber ambiental de todos nós: uma visão romântica e naturalista impede-nos de reformar nosso pensamento sobre a relação ser humano-natureza. Disponível em: <https://www.seer.furg.br/remea/article/view/3247>. Acesso em: 16 mar.2016.

TRISTÃO, M. A educação ambiental na formação de professores. 2. ed. São Paulo: Annablume; Vitória: Fapitec, 2008.

VASCONCELOS, M.A. O. Caracterização da prática da educação ambiental nas escolas de Aracaju. 2008. Dissertação (Mestrado). São Cristóvão, SE: UFS, 2008. 147p. 